\title{
CIUDADES, GENTES E INTERCAMBIOS EN LA MONARQUÍA HISPÁNICA EN LA EDAD MODERNA
}

\section{ROBERTO LÓPEZ VELA (ED.)}

Ediciones Universidad de Cantabria, Santander, 2019, 432 págs.

En 2016 se celebraba un Seminario en el que los componentes del proyecto HAR2012-39034-C03 Ciudades, gentes e intercambios en la Monarquía Hispánica en la EdadModerna, financiado por el Ministerio de Economía y Competitividad, exponían y debatían los resultados de las investigaciones de los tres sub-proyectos que lo conformaban. Las vicisitudes que siempre conlleva la edición han retrasado la publicación de los resultados de aquel seminario, que finalmente ven la luz recogidos en un libro que se estructura en un preámbulo y tres partes diferenciadas en las que se procede a una aproximación al mundo urbano desde la triple perspectiva del gobierno, la cultura y las finanzas.

Corresponde al investigador principal del proyecto coordinado, Roberto López Vela, realizar una síntesis de la trayectoria del proyecto. Presenta los objetivos del mismo, la metodología seguida, las aportaciones de cada uno de los sub-proyectos, las distintas líneas de investigación en las que prima la visión interdisciplinar y, por supuesto, los resultados obtenidos, en especial las publicaciones, que quedan recogidas en notas a pie de página. Partiendo como objetivo central del mundo urbano las temáticas abordadas son múltiples. Así, el gobierno municipal y su respuesta a tensiones jurisdiccionales, sociales y económicas. La movilidad humana, en especial de jóvenes y mujeres, entre ciudades con especial referencia a las transferencias culturales anexas. La ciudad y la regulación del mercado, con estudios sobre precios y salarios; el mundo del trabajo; y la actividad manufacturera. La incidencia de las finanzas reales sobre la ciudad: deuda pública y carga fiscal.

Tras este preámbulo, el primer bloque del libro, dedicado al gobierno urbano y sus élites, contiene tres aportaciones. La venta de oficios concejiles y el gobierno de las ciudades de Castilla: el acrecentamiento de 1543, cuya autoría corresponde a José Ignacio Fortea Pérez, que incide en como dicho proceso de acrecentamiento de oficios concejiles, junto con otras medidas relativas a la perpetuación de los cargos de gobierno local, dio lugar a una merma de la participación de la generalidad de los vecinos en la institución municipal, acentuándose su oligarquización. Señala aspectos como la amplia distribución geográfica de la medida; los precios alcanzados por las ventas en función de la significación de las ciudades y de la 
demanda existente en cada una de ellas; y la procedencia social de los adquirientes, generalmente pertenecientes a sectores con deseos de promocionar en la encorsetada sociedad de la época.

Gobernar las Cuatro Villas de la Costa: corregidores militares de Felipe IV (1621-1665), estudio desarrollado por María Barcina Abad, señalando el cambio en la elección de las personas que deberían ocupar dicho corregimiento de la costa cantábrica como consecuencia del ataque francés de 1639. Se escogieron militares de mayor graduación y, especialmente, con más experiencia bélica. El objetivo era doble: aumentar la capacidad defensiva de la zona e imponerse a las reticencias de los vecinos a las medidas tomadas más dolosas para el vecindario.

Héctor F. Sánchez Diego, presenta Entre regidores y mercaderes. Comportamientos y pautas de padrinazgo de las élites santanderinas del siglo XVIII, una aportación al estudio del cambio social experimentado en Santander a raíz de la evolución positiva de su economía en la segunda mitad del siglo XVIII. La metodología empleada busca captar dicha transformación social a través del estudio de los padrinos de los recién nacidos, comparando los periodos de 173035 y 1776-81. Destaca, en este segundo periodo como la élite local santanderina se abre a relacionarse con nuevos miembros en ascenso, gran parte de ellos de origen foráneo, a la vez que se van retrayendo del parentesco espiritual con miembros de los grupos populares.

La segunda parte del libro lleva el título de Culturas y representaciones urbanas, e incluye cuatro investigaciones. Roberto López Vela presenta un extenso y documentado estudio, Historiografía y ciudad. El debate sobre Toledo en el humanismo y la época confesional, en el que muestra el cambio que experimenta la identidad y representación de la ciudad de Toledo como consecuencia de dos hechos: el peso cada vez mayor de Madrid como capital de la monarquía y la significación de Toledo como sede del arzobispado primado de España en el periodo de predominio confesional, lo que llevaría a considerar Toledo como la segunda Roma.

La aportación de Fernando Suárez Galán, "El cielo tan cerca está de Galicia como de las Indias». Carreras y figuras episcopales a uno y otro lado del Atlántico en época Moderna, analiza dos figuras eclesiásticas en el tránsito de los siglos XVII y XVIII, una de origen mexicano que termino ocupando el arzobispado de Santiago de Compostela y otra oriunda de Galicia, que desempeñó el arzobispado de México. El estudio, además de los aspectos biográficos, incide en las relaciones entre la península y las Indias y en el modelo de santidad episcopal vigente en la época.

Entre la pervivencia y la corrupción de un deseo. Dos obras para casar doncellas, A Coruña, siglos XVI-XIX, recoge el trabajo que Ana María Sexto Barcia dedica a dos obras pías de la ciudad de La Coruña. Se desgrana su fundación; las cláusulas que reglamentan su funcionamiento y 
que muestran las pretensiones y preocupaciones de los fundadores; la administración desarrollada a lo largo del tiempo, que oscila entre la buena disposición, el desinterés y la corrupción; y los beneficios aportados a la sociedad en aras a combatir o mitigar la pobreza.

Este apartado concluye con el estudio de Rubén Castro Redondo sobre Las medidas superficiales de las poblaciones gallegas bajo el señorío urbano a mediados del siglo XVIII. Su objetivo principal es encontrar alguna razón que explicara y diera sentido al caos de medidas superficiales existente en Galicia (aunque es general para todos los territorios de la Monarquía) previo a la implantación del sistema métrico decimal. Su planteamiento es que frente a la heterogeneidad palpable es posible detectar cierta homogenización de medidas en lugares pertenecientes a una misma jurisdicción señorial, aunque dichos enclaves estuvieran en ámbitos territoriales distantes. Esa cierta homogenización se debería a que los señoríos ostentaban y ejercían competencias metrológicas.

Para finalizar, el tercer bloque del libro, bajo el título genérico de Monarquía, finanzas y ciudades, recoge cinco trabajos de marcado carácter económico. El primero, con la autoría de Ramón Lanza García, Carga tributaria, ciudadania y moral fiscal en la Castilla del siglo XVII, parte de una interesante reflexión sobre las conexiones entre la presión fiscal y las formas de gobierno y de representación política. Una mayor o menor carga fiscal es un elemento clave a tener en cuenta, pero también la percepción que sobre dicha fiscalidad pueda tener la comunidad en razón de su capacidad para intervenir en la misma y de las compensaciones obtenidas. Tras analizar la carga fiscal de forma comparada en Europa, se realiza una aproximación a la comunidad política en la España Moderna; se evalúan los límites del poder fiscal; y se sigue la evolución del sistema fiscal, incluyendo el siglo XVIII, con especial incidencia en la cuestión de la deuda pública.

José Ignacio Andrés Ucendo presenta un trabajo sobre La «media annata de juros» y el sistema fiscal y financiero castellano en el siglo XVII. En él, con los problemas metodológicos inherente al desconocimiento puntual de los ingresos y gastos totales de la monarquía en el siglo XVII, se plantea la importancia de lo recaudado por la media annata a efecto de incrementar los ingresos totales de la hacienda, pero, al mismo tiempo, se señala el descenso de estos en términos de reales de plata.

Transformaciones del crédito hipotecario en Santiago de Compostela a finales del Antiguo Régimen, de Francisco Cebreiro Ares, nos muestra a través del estudio de la documentación recogida en el Registro de Hipotecas, creado en 1768, los principales cambios que se pueden observar en las modalidades de crédito en Santiago de Compostela a finales del siglo XVIII. Destaca la paulatina significación de las obligaciones en detrimentos de los censos. Dichas obligaciones muestran el predominio de los comercial, pero también la mayor incidencia de 
las relaciones con un mundo rural que pasa de deudor a acreedor. Se incide en la menor incidencia del estamento eclesiástico y el papel destacado de los bienes de las mujeres en este mercado de crédito.

Mediante el análisis de distintos casos específicos Mónica F. Armesto, Los mercaderes de cruzada de la Corona de Castilla. Riesgos y quiebra en la ciudad de Santiago y su arzobispado (siglos XVII-XVIII), nos muestra la extensa problemática generada por los asentistas que arrendaban el cobro de la bula de cruzada, fruto de los altos riesgos que conllevaban dichos arrendamientos.

Para terminar, Juan Eloy Gelabert, Ciudades, gentes e intercambios en tiempos de tribulación (1595-1609), analiza el periodo bélico y de conversaciones de paz de 1595-1609 para relacionarlo con las transformaciones que se consolidarían en el comercio internacional, con la apertura de nuevas vías y mercados, en las que se verían implicados varios Estados y que romperían el tradicional monopolio de los reinos hispánicos.

En suma, no cabe duda de que los trabajos reunidos en esta obra colectiva ponen de manifiesto que es posible reivindicar la historia urbana como objeto renovado de investigación y elemento vivo del debate historiográfico. Se plantea una transformación temática y metodológica, propiciando nuevos enfoques y cambios de orientación, siendo fundamental el acercamiento a los problemas y cuestiones desde una perspectiva interdisciplinar y fomentando la colaboración y el trabajo común de los equipos implicados, en este caso pertenecientes a las Universidades de Cantabria, Santiago de Compostela y Autónoma de Madrid.

Por encima del agotamiento, todavía queda pendiente colmar muchos vacíos historiográficos en el estudio del mundo urbano. La amplitud de la dedicación en zonas como el noroeste peninsular, que abarca este libro, contrasta con el vacío historiográfico de otros territorios. E, igualmente, resta reforzar los estudios comparados interterritoriales, que nos ayuden a comprender el fenómeno urbano, su ámbito cultural y político-fiscal, en el conjunto de la monarquía española. Los trabajos incluidos en este libro muestran el camino a seguir. Y vista la riqueza de las posibilidades y conclusiones ofrecidas no faltaran candidatos dispuestos a recorrerlo.

Jesús Manuel González Beltrán

Universidad de Cádiz 